\title{
A 3-year observation of testosterone deficiency in Chinese patients with chronic heart failure
}

\author{
Ying Han ${ }^{1, *}$, Weiju Sun ${ }^{2, *}$, Guizhi Sun ${ }^{1}$, Xiaolu Hou ${ }^{1}$, Zhaowei Gong ${ }^{1}$, Jing $\mathbf{X u}^{1}$, \\ Xiuping Bai ${ }^{1}$ and Lu Fu' ${ }^{2}$ \\ ${ }^{1}$ Cardiovascular Department, The Fourth Affiliated Hospital of Harbin Medical University, Harbin 150001, China \\ ${ }^{2}$ Cardiovascular Department, The First Affiliated Hospital of Harbin Medical University, Harbin 150001, China \\ *These authors contributed equally to this work and should be considered co-first authors \\ Correspondence to: Lu Fu, email: fulunadia@aliyun.com \\ Xiuping Bai, email: baixiuping@medmail.com.cn
}

Keywords: testosterone deficiency, chronic heart failure, mortality, readmission

Received: April 26, $2017 \quad$ Accepted: July 12, $2017 \quad$ Published: August 02, 2017

Copyright: Han et al. This is an open-access article distributed under the terms of the Creative Commons Attribution License 3.0 (CC BY 3.0), which permits unrestricted use, distribution, and reproduction in any medium, provided the original author and source are credited.

\section{ABSTRACT}

Testosterone deficiency is present in a certain proportion men with chronic heart failure (CHF). Low testosterone levels in American and European patients with CHF lead to the high mortality and readmission rates. Interestingly, this relationship has not been studied in Chinese patients. To this end, 167 Chinese men with CHF underwent clinical and laboratory evaluations associated with determinations of testosterone levels. Total testosterone (TT) levels and sex hormone-binding globulin were measured by chemiluminescence or immunoassays assays and free testosterone (FT) levels were calculated, Based upon results from these assays, patients were divided into either a low testosterone (LT; $n=93$ ) or normal testosterone (NT; $n=74$ ) group. Subsequently, records from each patient were reviewed over a follow-up duration of at least 3 years. Patients in the LT group experienced worse cardiac function and a higher prevalence of etiology (ischemic vs. no ischemic) and comorbidity (both $P<0.05$ ). In addition, readmission rates of patients in the LT group were higher than that of patients in the NT group ( $3.32 \pm 1.66$ VS $1.57 \pm 0.89)$. Overall, deficiencies in FT levels were accompanied with increased mortalities (HR $=6.301,95 \%$ CI $3.187-12.459, P<.0001)$.

\section{INTRODUCTION}

Chronic heart failure (CHF) is a major health problem throughout the world as the final outcome of almost all cardiovascular diseases [1-11]. It is associated with a high rate of hospitalization and a devastating prognosis, despite the availability of modern combinational therapies. The mortality rate of $\mathrm{CHF}$ is higher than that of most cancers, and more than $50 \%$ of CHF patients die within 5 years of diagnosis [12]. Different clinical feature were observed in men and women with $\mathrm{CHF}$, such as symptoms, response to therapies, and mortality [13-15]. Statistical results show that more number of women than men suffer from CHF. Whereas, women with CHF can benefit much more from medication and have a higher age-adjusted survival rate than men. Therefore, it is reasonable to present the hypothesis that sex hormones may play a role in CHF.
Previous studies [16-18] have shown that a testosterone deficiency existed in men with $\mathrm{CHF}$, and serum testosterone correlated inversely with ventricular ejection fraction, hemodynamics and exercise capacity. Moreover, deficiencies in anabolic hormones (testosterone, dehydroepiandrosterone sulfate, and insulin-like growth factor-1) can serve as predictors for poor prognosis [19]. Further evidence for this has emerged from several trials [20-22] demonstrating that testosterone replacement therapy is associated with significant increases in exercise tolerance, improvement of symptoms and amendments in the quality-of-life. To our knowledge, there are few data $[19,23-25]$ on the relationship between testosterone levels and 3-year outcomes (mortality and readmission rates) in men with CHF and yielded conflicting results. The aim of the our study was to evaluate the prospective effect of testosterone deficiency on the 3-year mortality and readmission rates in male patients hospitalized with CHF. 


\section{RESULTS}

\section{Hormone levels and serum parameters}

Baseline characteristics of the 167 Chinese patients with CHF are summarized in Table 1. Patients in LT group were characterized by older age, higher systolic blood pressure, advanced New York Heart Association (NYHA) class, lower left ventricular ejection fraction (LVEF), lager left ventricular end diastolic diameter (LVEDD), decreased hemoglobin, decreased estimated glomerular filtration rate (GFR), increased serum B-type natriuretic peptide (BNP) level, and higher prevalence of etiology(ischemic vs. no ischemic) and comorbidities (atrial fibrillation, hypertension and diabetes). All the patients were treated with standard drug regimens, including diuretics, angiotensin-converting-enzyme (ACE) inhibitors or angiotensin receptor blocker (ARB), $\beta$-Blockers, digoxin and Spironolactone.

\section{Clinical outcomes}

At the end of the 3-year follow-up period, there were 47 deaths ( $28 \%$ of all patients enrolled) with all deaths being cardiovascular. The LT group experienced a significantly higher mortality rate (42/93) as compared to the NT group (5/74) at this 3-year follow-up period (Table 2). This mortality rate was significantly greater in the LT versus NT group $\left(\chi^{2}=30.60, P<.0001\right)$ as shown in the Kaplan-Meier curves for cumulative survival rates of patients in the two groups (Figure 1). Of surviving patients, $86 \%$ experienced at least one unplanned admission resulting from a worsening of heart failure. Readmission rates were significantly greater in the LT
(3.32 \pm 1.66$)$ as compared to the NT $(1.57 \pm 0.89)$ group (Table 2, Figure 2). Figure 3 shows the Kaplan-Meier curves for cumulative readmission rates for patients in the two groups. The LT group had a significantly higher readmission rates compared to the NT group $\left(\chi^{2}=56.57\right.$, $P<.0001)$.

\section{Prognostic factors}

Prognostic results of the univariate Cox proportional hazard analysis to predict cardiac death are shown in Table 3. Reduced levels of TT and FT in serum were identified as available predictors of mortality in men with CHF (TT, HR $=0.885,95 \%$ CI 0.829-0.945, $P=.0003$; $\mathrm{FT}, \mathrm{HR}=13.360,95 \%$ CI 7.149-24.967, $P<.0001)$. In multivariable models, we included nearly all the variables that were involved in the univariate analyses. The final model included 3 significant independent predictors consisting of LVEF (HR $=1.075,95 \%$ CI $1.026-1.127$, $P=0.0003)$, serum FT $(\mathrm{HR}=6.301,95 \%$ CI $3.187-$ $12.459, P<.0001)$, and GFR (HR $=0.967,95 \% \mathrm{CI} 0.937-$ $0.998, P=0.0348$ ) (Table 4).

\section{DISCUSSION}

The salient results in this study of male Chinese patients with CHF include two major findings. First, CHF patients with decreased TT and FT concentrations experienced worse heart function compared with that in normal individuals. Second, a deficiency in testosterone was an independent risk predictor for mortality and readmission rates in men hospitalized with CHF,

Several published studies have suggested that patients with CHF had low androgen levels. In the present

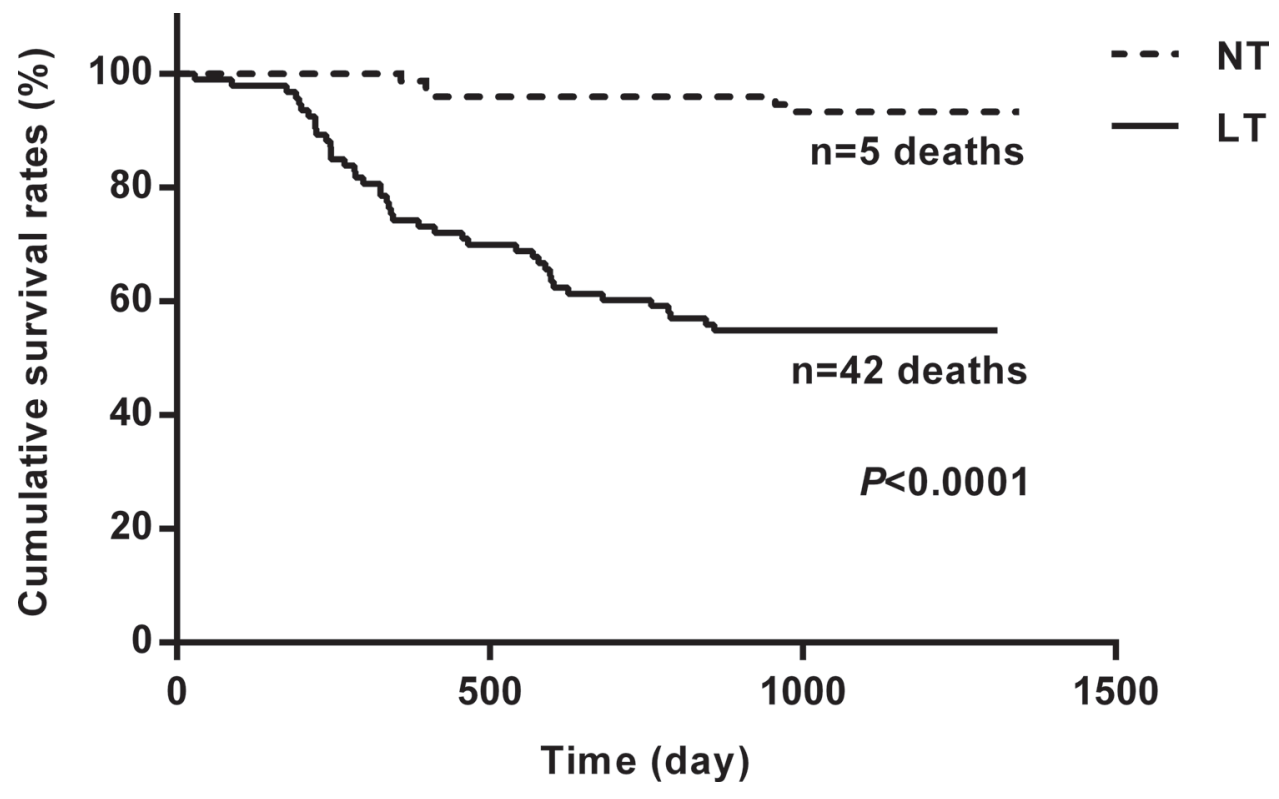

Figure 1: Kaplan-Meier curves for cumulative survival rates of patients in the two groups. The low testosterone group showed significantly higher mortality rates as compared with that of the normal testosterone group $(P<.0001)$. 
Table 1: Physical, clinical, and hormonal characteristics of patients with heart failure at the first admission

\begin{tabular}{|c|c|c|c|c|}
\hline Variables & Low Testosterone $(n=93)$ & Normal Testosterone $(n=74)$ & statistics & $P$ value \\
\hline Age, $y$ & $69(60-75)$ & $60(50-71)$ & 3.43 & 0.0006 \\
\hline NYHA class, $\mathrm{n} \%$ & & & 5.78 & $<.0001$ \\
\hline II & $5(5.38)$ & $35(47.30)$ & & \\
\hline III & $42(45.16)$ & $24(32.43)$ & & \\
\hline IV & $46(49.46)$ & $15(20.27)$ & & \\
\hline LVEF, \% & $39.0(32.0-42.0)$ & $44.5(39.0-46.0)$ & 4.75 & $<.0001$ \\
\hline LVEDD, mm & $64(60-68)$ & $60(58-65)$ & 3.02 & 0.0025 \\
\hline $\mathrm{TT}, \mathrm{ng} / \mathrm{dL}$ & $239.14(197.30-281.01)$ & $401.19(332.14-502.63)$ & 11.08 & $<.0001$ \\
\hline $\mathrm{FT}, \mathrm{pmol} / \mathrm{L}$ & $110.36(81.17-133.23)$ & $175.15(146.68-201.78)$ & 6.73 & $<.0001$ \\
\hline SBP, mmHg & $158(138-169)$ & $135(118-156)$ & 3.60 & 0.0003 \\
\hline Ischemic, $\mathrm{n} \%$ & $78(83.87)$ & $50(67.57)$ & 6.12 & 0.0134 \\
\hline \multicolumn{5}{|l|}{ Comorbidities, $\mathrm{n} \%$} \\
\hline Atrial fibrillation & $37(39.78)$ & $12(16.22)$ & 11.04 & 0.0009 \\
\hline Hypertension & $73(78.49)$ & $40(54.05)$ & 11.25 & 0.0008 \\
\hline Diabetes & $48(51.61)$ & $14(18.92)$ & 18.87 & $<.0001$ \\
\hline \multicolumn{5}{|l|}{ Medication, $\mathrm{n} \%$} \\
\hline ACEI/ARB & $74(79.57)$ & $71(95.95)$ & 9.66 & 0.0019 \\
\hline$\beta$-blocker & $83(59.25)$ & $65(87.84)$ & 0.08 & 0.7757 \\
\hline Digoxin & $43(46.24)$ & $24(32.43)$ & 3.27 & 0.0706 \\
\hline Diuretic & $90(96.77)$ & $43(58.11)$ & 38.00 & $<.0001$ \\
\hline \multicolumn{5}{|l|}{ Laboratory variables } \\
\hline $\mathrm{GFR}, \mathrm{mL} \cdot \mathrm{min}^{-1} \cdot 1.73 \mathrm{~m}^{2}$ & $65.8(54.8-77.2)$ & $84.9(74.9-90.8)$ & 6.36 & $<.0001$ \\
\hline BNP, pg/mL & $2105.0(1368.0-2968.0)$ & $1134.5(945.0-1697.0)$ & 6.22 & $<.0001$ \\
\hline Hemoglobin, g/L & $160(146-169)$ & $151(138-162)$ & 2.68 & 0.0073 \\
\hline
\end{tabular}

Results are presented as median (with upper and lower quartiles) or \% where appropriate. NYHA, New York Heart Association; LVEF: Left ventricular ejection fraction; LVEDD: left ventricular end diastolic diameter; TT: Total testosterone; FT: Free testosterone; ACE-I/ARB: Angiotensin-converting enzyme inhibitor/angiotensin receptor blocker; GFR: Glomerular filtration rate; BNP: B-type natriuretic peptide.

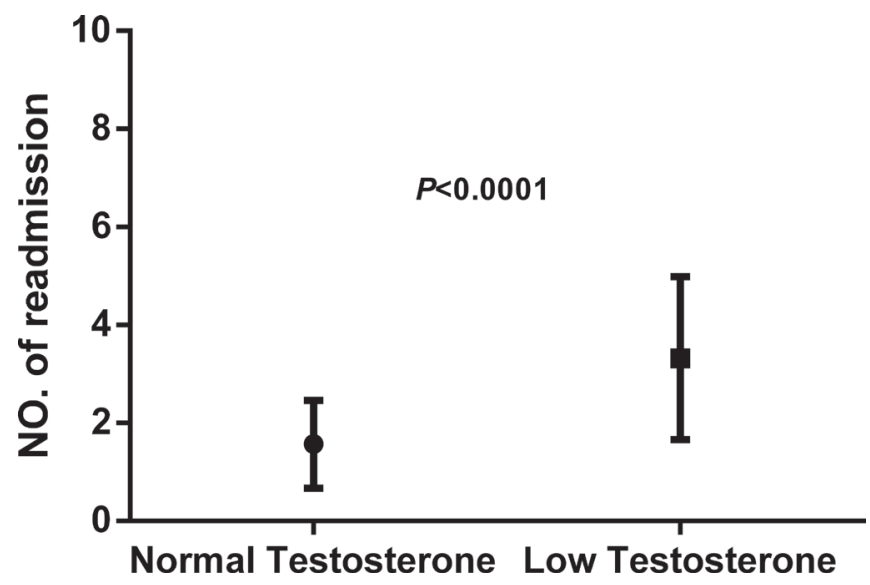

Figure 2: Readmission rates as determined over the 3-year follow-up period in patients with heart failure. The low testosterone group showed significantly higher readmission rates as compared with that of the normal testosterone group $(P<.0001)$. 
Table 2: Clinical outcomes

\begin{tabular}{|c|c|c|c|c|}
\hline Variables & Low Testosterone $(n=93)$ & Normal Testosterone $(n=74)$ & statistics & $P$ value \\
\hline Age,y & $66.75 \pm 11.63$ & $60.09 \pm 12.66$ & 3.53 & 0.0005 \\
\hline follow-up time,d & $\begin{array}{l}818.2 \pm 406.6 \\
1089(345-1154)\end{array}$ & $\begin{array}{l}1146.0 \pm 178.7 \\
1147(1111-1248)\end{array}$ & 5.06 & $<.0001$ \\
\hline Readmission times & $\begin{array}{l}3.32 \pm 1.66 \\
3(2-4)\end{array}$ & $\begin{array}{l}1.57 \pm 0.89 \\
1(1-2)\end{array}$ & 8.72 & $<.0001$ \\
\hline death & $42(45.16)$ & $5(6.76)$ & 30.06 & $<.0001$ \\
\hline
\end{tabular}

study, we determined serum levels of TT, which is the major component of androgens, and as well as FT, which reflects the most active fraction of circulating gonadal androgens and is directly related to biological effects on target tissues. Here we report that patients in LT group had worse cardiac function and higher prevalence of etiology (ischemicvs. no ischemic) and comorbidities (atrial fibrillation, hypertension and diabetes).

An important component of our current findings is that this androgen deficiency in men with CHF is not only a simple surrogate of disease severity, but also an independent risk factor of prognosis. Data from previous studies have suggested that testosterone insufficiency was associated with an increasing risk of death due to all cardiovascular related diseases in men [26-28]. Jankowska et al. [19] investigated the prevalence and prognostic consequences of deficiencies in circulating TT, FT, dehydroepiandrosterone sulfate (DHEAS), and insulin-like growth factor-1 in men with CHF. Their results showed that men with $\mathrm{CHF}$ and normal levels of all anabolic hormones experienced the best 3-year survival rate (83\%) as compared to those with deficiencies in 1 (74\% survival rate), 2 (55\% survival rate), or all 3 (27\% survival rate) anabolic endocrine indices. However, another two studies [24, 25] found that after adjustment of variables that were associated with both the exposure and the outcome, neither TT nor FT, DHEAS or sex hormone-binding globulin (SHBG) represent independent predictors of mortality risk. More recently, results from Marcelo et al. [23] in their multivariable analyses of 110 male patients with $\mathrm{CHF}$, also provide support for the concept that LT is an independent risk factor for hospital readmission within 90 days and increased mortality in patients with HF. In our present study, as well as in that reported by Jankowska et al. and Marcelo et al., reduced levels of TT and FT were related to an increased 3-year mortality rate (all cardiovascular deaths) in men with CHF. Taken together, these results suggest that androgen deficiency is likely to be one of the reasons leading to aggravation and deterioration in the progression of heart failure. However, others $[5,6]$ have found that after adjustment of variables that were associated with both the exposure and the outcome, neither TT nor FT, DHEAS or sex hormone-binding globulin (SHBG) represent independent predictors of mortality risk. Such disparate findings can in part, be explained by differences in the samples of CHF patients enrolled and measurements of TT levels. For example, the sample studied by Guder et al. $[5,6]$ included a large proportion of CHF patients with preserved LVEF, unlike those in the other studies. The



Figure 3: Kaplan-Meier curves for cumulative readmission rates for patients in the two groups. The low testosterone group showed significantly higher readmission rates as compared with that of the normal testosterone group $\left(\chi^{2}=56.57, P<.0001\right)$. 
Table 3: Single-predictor models of the Cox proportional hazard analysis for mortality

\begin{tabular}{lllllll}
\hline Variables & B & SE & $\chi^{2}$ & HR & 95\% CI & P value \\
\hline Age,y & 0.0045 & 0.0118 & 0.1445 & 1.004 & $0.982-1.028$ & 0.7038 \\
NYHA class & 2.5400 & 0.4181 & 36.9092 & 12.679 & $5.588-28.772$ & $<.0001$ \\
LVEF, \% & -0.1703 & 0.0185 & 84.6558 & 0.843 & $0.813-0.875$ & $<.0001$ \\
LVEDD, mm & 0.1183 & 0.0158 & 55.7897 & 1.126 & $1.091-1.161$ & $<.0001$ \\
TT, ng/dL & 2.1715 & 0.4737 & 21.0173 & 8.771 & $3.466-22.194$ & $<.0001$ \\
FT, pmol/L & 2.5923 & 0.3190 & 66.0283 & 13.360 & $7.149-24.967$ & $<.0001$ \\
SBP, mmHg & -0.0005 & 0.0058 & 0.0085 & 0.999 & $0.988-1.011$ & 0.9267 \\
Ischemic & -0.0482 & 0.3446 & 0.0196 & 0.953 & $0.485-1.872$ & 0.8887 \\
Atrial fibrillation & 0.4733 & 0.3003 & 2.4851 & 1.605 & $0.891-2.892$ & 0.1149 \\
Hypertension & -0.1333 & 0.3079 & 0.1874 & 0.875 & $0.479-1.600$ & 0.6651 \\
Diabetes & 1.1237 & 0.2978 & 14.2425 & 3.076 & $1.716-5.514$ & 0.0002 \\
ACEI/ARB & -1.3879 & 0.3206 & 18.7353 & 0.250 & $0.133-0.468$ & $<.0001$ \\
$\beta$-blocker & 0.7487 & 0.5968 & 1.5741 & 2.114 & $0.656-6.810$ & 0.2096 \\
Digoxin & 1.0142 & 0.3003 & 11.4071 & 2.757 & $1.531-4.967$ & 0.0007 \\
Diuretic & 2.0411 & 0.7226 & 7.9774 & 7.699 & $1.868-31.734$ & 0.0047 \\
GFR,mL·min ${ }^{-1} \cdot 1.73 \mathrm{~m}^{2}$ & -0.05911 & 0.0078 & 57.3415 & 0.943 & $0.928-0.957$ & $<.0001$ \\
BNP, pg/mL & 0.0012 & 0.0001 & 102.6056 & 1.001 & $1.001-1.001$ & $<.0001$ \\
Hemoglobin, g/L & 0.00134 & 0.0062 & 0.0470 & 0.999 & $0.987-1.011$ & 0.8284 \\
\hline
\end{tabular}

NYHA, New York Heart Association; LVEF: Left ventricular ejection fraction; LVEDD: left ventricular end diastolic diameter; TT: Total testosterone; FT: Free testosterone; ACE-I/ARB: Angiotensin-converting enzyme inhibitor/angiotensin receptor blocker; GFR: Glomerular filtration rate; BNP: B-type natriuretic peptide.

Table 4: Multivariable models of Cox proportional hazard analyses for mortality

\begin{tabular}{lllllll}
\hline Variables & B & SE & $\chi^{2}$ & HR & $\mathbf{9 5 \%}$ CI & $P$ value \\
\hline LVEF & -0.1222 & 0.0336 & 13.2309 & 0.885 & $0.829-0.945$ & 0.0003 \\
FT & 1.8407 & 0.3478 & 28.0117 & 6.301 & $3.187-12.459$ & $<.0001$ \\
GFR & -0.0339 & 0.0161 & 4.4534 & 0.967 & $0.937-0.998$ & 0.0348 \\
\hline
\end{tabular}

The meaningful variables in the multivariable models were listed. LVEF: Left ventricular ejection fraction; TT: Total testosterone; FT: Free testosterone; GFR: Glomerular filtration rate.

measurement of TT levels in the study by Wu et al. $[5,6]$ used a electrochemiluminescence assay, which may have resulted in an overestimation of TT levels. In addition, differences in parameters measured among these studies can contribute to contrasting conclusions. In the study by Jankowska et al. measures of additional hormones, such as DHEAS and insulin-like growth factor-1 were included in their analysis, while the study by Guder et al. included additional prognostic measures, such as medication and inflammatory markers, that were not included in Jankowska et al. There are more additional prognostic variables including the Comorbidities.

It is well known that testosterone exerts effects on contractile function of myocardium, vasodilation, insulin resistance, inflammation, coagulation, obesity, endothelial function and alteration in skeletal muscle [29-35]. In addition, testosterone concentration in serum reflects one aspect of anabolic insufficiency. Anabolic/ catabolic imbalances not only can result in the activation of catabolism but the inhibition of anabolism, as well as the activation of the neuroendocrine and cytokine systems, which play an important role in the pathological processes of CHF. Such imbalances are related to the symptoms, signs and cardiac cachexia [36]. Therefore, it seems likely that the prognosis and high readmission rates associated with testosterone deficiency are the consequences of various and complex mechanisms that await further research [37, 38]. 


\section{MATERIALS AND METHODS}

\section{Subjects}

The study was performed between September 2009 and October 2011 in male Chinese patients hospitalized with CHF in Harbin. Male patients $(N=167)$, aged 36 to 87 years with NYHA functional class II, III or IV (40/66/61), participated in the study. The criteria for study enrollment were as follows: $>6$ month symptomatic CHF; left ventricular ejection fraction $(\mathrm{LVEF}) \leq 45 \%$ as assessed by echocardiogramphy; clinical stability and standard medications for at least 1 month preceding the study; no testosterone replacement or drugs that could affect testosterone levels, such as finasteride, opiates, glucocorticoids and anticonvulsants. In addition, enrollment required that the patients have an absence of heavy alcohol consumption, nephrotic syndrome, liver cirrhosis or cancer history.

The study protocol was approved by the ethics committees of the participating hospitals and all patients provided written informed consent.

\section{Hormonal assays and laboratory measurements}

Venous blood samples were collected in the morning between 06:00 and 07:00 following an overnight fast and after a supine rest of at least 15 minutes on the second day after hospital admission. Serum concentrations of total testosterone (TT) were measured by chemiluminescence (Siemens Corp., USA). The inter and intra assay variability coefficients for TT were $2.5 \%$ and $5.8 \%$, respectively. Serum levels of SHBG were measured with ELISA (BL, Hamburg, Germany), and the inter and intra-assay variability coefficients were $5.2 \%$ and $3.0 \%$, respectively. Serum levels of free testosterone (FT) were then calculated using the validated equation of Vermeulen et al. [39]. Testosterone deficiency, referred to as hypogonadism, was defined as a total testosterone $<300 \mathrm{ng} / \mathrm{dL}$ and free testosterone $<131 \mathrm{pmol} / \mathrm{L}[40,41]$.

All CHF patients underwent clinical and laboratory evaluations, including physical examination, electrocardiogram, echocardiography, chest X-ray, full blood count, serum electrolytes and, if necessary, coronary angiography. Measurements, such as BNP and hemoglobin, were performed by the hospital biochemistry laboratory. Estimated GFR was calculated using the formula from the Modification of Diet in the Renal Disease Study Group.

\section{Clinical follow-up}

Patients were reviewed regularly, with a followup duration extending for at least 3 years. The study investigators were provided with information regarding mortality and readmission rates (as of October 30, 2014) directly from patients and their relatives by periodic phone calls, or from the hospital system. No patient was lost to follow-up. The two endpoints included: (1) worsening of heart failure as indicated by readmission and/or (2) cardiac death, defined as death from worsening heart failure or sudden cardiac death.

\section{Statistical analysis}

Most variables showed a skewed distribution and were therefore expressed as medians with lower and upper quartiles. Comparisons between the two groups were made using the Mann-Whitney $U$ testor the $\chi 2$ test, where appropriate. The association of total and free testosterone levels with all cause of mortality was determined by Cox proportional hazards regression. The following variables were included in the Single-predictor models of the Cox proportional hazard analysis: age, etiology, NYHA class, LVEF, LVEDD, systolic blood pressure, comorbidities, medication, GFR, plasma BNP, hemoglobin and serum levels of TT and FT. During construction of the multivariable models, variables that may be significant predictors of survival according to the Single-predictor models and the clinic, were included in the analyses. These variables included: age, etiology, NYHA class, LVEF, LVEDD, systolic blood pressure, comorbidities, medication, GFR, BNP levels, and serum levels of TT and FT. In order to estimate the effect of serum levels of TT and FT on 3-year survival rates and readmission rates, Kaplan-Meier curves for cumulative survival and readmission rates were constructed for patients in the LT and NT groups. Comparisons of survival rates were tested with the Cox-Mantel log-rank test. Differences with a value of $P<0.05$ were considered required for results to be statistically significant. The data analysis was conducted by an independent university-based statistician using SPSS 19.0 (Statistical Package for the Social Sciences 19.0, IBM SPSS company, USA).

\section{CONCLUSIONS}

In this sample of Chinese men with CHF, testosterone deficiency served as a predictor for the high rates of 3-year mortality and readmission. Our findings suggested the potential for beneficial effects of testosterone in the treatment of this condition.

\section{Study limitation}

There remain a number of limitations related to this study. First, the sample size was relatively small. Therefore, these data should be confirmed as based upon a larger sample of patients and preferably contain all NYHA functional classes especially class I. Second, patients enrolled in this study were limited to CHF patients with CHF who had experienced a significant cardiac event requiring hospitalization. Whether these findings would also be applicable to outpatients with stable clinical manifestations should be further investigation. Third, levels of FT and TT were measured at only one time point. 
It is not known whether FT and TT levels may fluctuate in CHF patients with CHF over the 3-year follow-up period. Nor is it known whether FT and TT levels decreased in NT patients over this 3-year period. Finally, our currents results do not provide any information regarding mechanisms by which testosterone deficiency predicts poor outcome and high readmission rate in men with CHF. Indeed, such mechanisms may involve a multi-factorial process and remains a subject for further investigation.

\section{Author contributions}

YH, WS, XB and LF conceived and designed the experiments. YH, WS, GS, XH, ZG, JX, DG, FM, RC, and YL analyzed data. YH and WS wrote this manuscript. All authors read and approved the final manuscript.

\section{ACKNOWLEDGMENTS}

This research was supported in part by Science and Technology Research Project of Education Department of Heilongjiang Province (12521171), and Scientific Research Project of Health and Life Committee of Heilongjiang Province (2016-191).

\section{CONFLICTS OF INTEREST}

The authors declare that they have no conflicts of interest.

\section{REFERENCES}

1. Cheng L, Wang G, Li J, Zhang T, Xu P, Wang Y. SIDD: A Semantically Integrated Database towards a Global View of Human Disease. PLoS One. 2013; 8:e75504.

2. Cheng L, Li J, Ju P, Peng J, Wang Y. SemFunSim: a new method for measuring disease similarity by integrating semantic and gene functional association. PLoS One. 2014; 9:e99415.

3. Cheng L, Jiang Y, Wang Z, Shi H, Sun J, Yang H, Zhang S, Hu Y, Zhou M. DisSim: an online system for exploring significant similar diseases and exhibiting potential therapeutic drugs. Sci Rep. 2016; 6:30024.

4. Cheng L, Sun J, Xu WD, Dong L, Hu Y, Zhou M. OAHG: an integrated resource for annotating human genes with multi-level ontologies. Sci Rep. 2016; 10:34820.

5. Liu Y, Zeng X, He Z, Zou Q. Inferring microRNA-disease associations by random walk on a heterogeneous network with multiple data sources. IEEE/ACM Trans Comput Biol Bioinform. 2016. [Epub ahead of print].

6. Zeng X, Liao Y, Liu Y, Zou Q. Prediction and validation of disease genes using HeteSim Scores. IEEE/ACM Trans Comput Biol Bioinform. 2016. [Epub ahead of print].

7. Zeng $\mathrm{X}$, Zhang $\mathrm{X}$, Zou Q. Integrative approaches for predicting microRNA function and prioritizing disease- related microRNA using biological interaction networks. Brief Bioinform. 2016; 17:193-203.

8. Zou Q, Li J, Song L, Zeng X, Wang G. Similarity computation strategies in the microRNA-disease network: a survey. Brief Funct Genomics. 2016; 15:55-64.

9. Cheng L, Shi H, Wang Z, Hu Y, Yang H, Zhou C, Sun J, Zhou M. IntNetLncSim: an integrative network analysis method to infer human lncRNA functional similarity. Oncotarget. 2016; 7:47864-47874. https://doi.org/10.18632/ oncotarget.10012.

10. Hu Y, Zhou M, Shi H, Ju H, Jiang Q, Cheng L. InfDisSim: A novel method for measuring disease similarity based on information flow. IEEE/ACM Trans Comput Biol Bioinform. 2016; 20-26.

11. Peng J, Xue H, Shao Y, Shang X, Wang Y, Chen J. A novel method to measure the semantic similarity of HPO terms. Int J Data Mining and Bioinformatics. 2017. [Epub ahead of print].

12. Levy D, Kenchaiah S, Larson MG, Benjamin EJ, Kupka MJ, Ho KK, Murabito JM, Vasan RS. Long-term trends in the incidence of and survival with heart failure. N Engl J Med. 2002; 347:1397-1402.

13. Ghali JK, Krause-Steinrauf HJ, Adams KF, Khan SS, Rosenberg YD, Yancy CW, Young JB, Goldman S, Peberdy MA, Lindenfeld J. Gender differences in advanced heart failure: insights from the BEST study. J Am Coll Cardiol. 2003; 42:2128-2134.

14. Majahalme SK, Baruch L, Aknay N, Goedel-Meinen L, Hofmann M, Hester A, Prescott MF, Feliciano N; Val-HeFT Study Investigators. Comparison of treatment benefit and outcome in women versus men with chronic heart failure (from the Valsartan Heart Failure Trial). Am J Cardiol. 2005; 95:529-532.

15. O’Meara E, Clayton T, McEntegart MB, McMurray JJ, Piña IL, Granger CB, Ostergren J, Michelson EL, Solomon SD, Pocock S, Yusuf S, Swedberg K, Pfeffer MA; CHARM Investigators. Sex differences in clinical characteristics and prognosis in a broad spectrum of patients with heart failure: results of the Candesartan in Heart failure: Assessment of Reduction in Mortality and morbidity (CHARM) program. Circulation. 2007; 115:3111-3120.

16. Agapitou V, Dimopoulos S, Kapelios C, Karatzanos E, Manetos C, Georgantas A, Ntalianis A, Terrovitis J, Karga $\mathrm{H}$, Nanas S. Hormonal imbalance in relation to exercise intolerance and ventilatory inefficiency in chronic heart failure. J Heart Lung Transplant. 2013; 32:431-436.

17. Bocchi EA, Carvalho VO, Guimaraes GV. Inverse correlation between testosterone and ventricle ejection fraction, hemodynamics and exercise capacity in heart failure patients with erectile dysfunction. Int Braz J Urol. 2008; 34:302-312.

18. Giagulli VA, Guastamacchia E, De Pergola G, Iacoviello $\mathrm{M}$, Triggiani V. Testosterone deficiency in male: a risk factor for heart failure. Endocr Metab Immune Disord Drug Targets. 2013; 13:92-99. 
19. Jankowska EA, Biel B, Majda J, Szklarska A, Lopuszanska M, Medras M, Anker SD, Banasiak W, Poole-Wilson PA, Ponikowski P. Anabolic deficiency in men with chronic heart failure: prevalence and detrimental impact on survival. Circulation. 2006; 114:1829-1837.

20. Pugh PJ, Jones TH, Channer KS. Acute haemodynamic effects of testosterone in men with chronic heart failure. Eur Heart J. 2003; 24:909-915.

21. Pugh PJ, Jones RD, West JN, Jones TH, Channer KS. Testosterone treatment for men with chronic heart failure. Heart. 2004; 90:446-447.

22. Malkin CJ, Pugh PJ, West JN, van Beek EJ, Jones TH, Channer KS. Testosterone therapy in men with moderate severity heart failure: a double-blind randomized placebo controlled trial. Eur Heart J. 2006; 27:57-64.

23. Santos MR, Sayegh AL, Groehs RV, Fonseca G, Trombetta IC, Barretto AC, Arap MA, Negrao CE, Middlekauff HR, Alves MJ. Testosterone deficiency increases hospital readmission and mortality rates in male patients with heart failure. Arq Bras Cardiol. 2015; 105:256-264.

24. Wu HY, Wang XF, Wang JH, Li JY. Testosterone level and mortality in elderly men with systolic chronic heart failure. Asian J Androl. 2011; 13:759-763.

25. Guder G, Frantz S, Bauersachs J, Allolio B, Ertl G, Angermann CE, Stork S. Low circulating androgens and mortality risk in heart failure. Heart. 2010; 96:504-509.

26. Oskui PM, French WJ, Herring MJ, Mayeda GS, Burstein $\mathrm{S}$, Kloner RA. Testosterone and the cardiovascular system: a comprehensive review of the clinical literature. J Am Heart Assoc. 2013; 2:e00272.

27. Khaw KT, Dowsett M, Folkerd E, Bingham S, Wareham N, Luben R, Welch A, Day N. Endogenous testosterone and mortality due to all causes, cardiovascular disease, and cancer in men: European prospective investigation into cancer in Norfolk (EPIC-Norfolk) Prospective Population Study. Circulation. 2007; 116:2694-2701.

28. Tambo A, Roshan MH, Pace NP. Testosterone and Cardiovascular Disease. Open Cardiovasc Med J. 2016; 10:1-10.

29. Golden KL, Marsh JD, Jiang Y, Brown T, Moulden J. Gonadectomy of adult male rats reduces contractility of isolated cardiac myocytes. Am J Physiol Endocrinol Metab. 2003; 285:E449-453.

30. Er F, Michels G, Brandt MC, Khan I, Haase H, Eicks M, Lindner M, Hoppe UC. Impact of testosterone on cardiac L-type calcium channels and $\mathrm{Ca} 2+$ sparks: acute actions antagonize chronic effects. Cell Calcium. 2007; 41:467-477.

31. Malkin CJ, Jones RD, Jones TH, Channer KS. Effect of testosterone on ex vivo vascular reactivity in man. Clin Sci (Lond). 2006; 111:265-274.
32. Malkin CJ, Pugh PJ, Jones RD, Kapoor D, Channer KS, Jones $\mathrm{TH}$. The effect of testosterone replacement on endogenous inflammatory cytokines and lipid profiles in hypogonadal men. J Clin Endocrin Metab. 2004; 89:3313-3318.

33. Kim C, Bebu I, Braffett B, Cleary PA, Arends V, Steffes M, Wessells H, Orchard T, Sarma AV, Group DER. Testosterone and cardiac mass and function in men with type 1 diabetes in the Epidemiology of Diabetes Interventions and Complications Study (EDIC). Clin Endocrinol. 2016; 84:693-699.

34. Stout M, Tew GA, Doll H, Zwierska I, Woodroofe N, Channer KS, Saxton JM. Testosterone therapy during exercise rehabilitation in male patients with chronic heart failure who have low testosterone status: a double-blind randomized controlled feasibility study. Am Heart J. 2012; 164:893-901.

35. Volterrani M, Rosano G, Iellamo F. Testosterone and heart failure. Endocrine. 2012; 42:272-277.

36. von Haehling S, Doehner W, Anker SD. Nutrition, metabolism, and the complex pathophysiology of cachexia in chronic heart failure. Cardiovasc Res. 2007; 73:298-309.

37. Jiang Q, Jin S, Jiang Y, Liao M, Feng R, Zhang L, Liu G, Hao J. Alzheimer's Disease Variants with the GenomeWide Significance are Significantly Enriched in Immune Pathways and Active in Immune Cells. Mol Neurobiol. 2016:1-7.

38. Liu G, Jiang Q. Alzheimer's disease CD33 rs3865444 variant does not contribute to cognitive performance. Proc Natl Acad Sci U S A. 2016; 113:201600852.

39. Vermeulen A, Verdonck L, Kaufman JM. A critical evaluation of simple methods for the estimation of free testosterone in serum. J Clin Endocrinol Metab. 1999; 84:3666-3672.

40. Huhtaniemi IT, Tajar A, Lee DM, O’Neill TW, Finn JD, Bartfai G, Boonen S, Casanueva FF, Giwercman A, Han TS, Kula K, Labrie F, Lean ME, et al. Comparison of serum testosterone and estradiol measurements in 3174 European men using platform immunoassay and mass spectrometry; relevance for the diagnostics in aging men. Eur J Endocrinol. 2012; 166:983-991.

41. Wang C, Catlin DH, Demers LM, Starcevic B, Swerdloff RS. Measurement of total serum testosterone in adult men: comparison of current laboratory methods versus liquid chromatography-tandem mass spectrometry. J Clin Endocrinol Metab. 2004; 89:534-543. 